\title{
Forensic neuropsychological assessment: clinical case of depression and working incapacity
}

\author{
Avaliação neuropsicológica forense: caso clínico de \\ depressão e incapacidade para o trabalho \\ Camila Monti', Fabiana Saffi', Daniel Martins de Barros', Alvaro Machado Dias², Henrique Teruo Akiba33, \\ Antonio de Pádua Serafim 1,4
}

\begin{abstract}
Issues related to mental health in relation to court matters have increasingly required the participation of the psychologist. We present the use of forensic neuropsychological assessment in a case of retirement reversal. Incapacity was attested due to disability resulting from depression of a 35-year-old attorney, and the case was forwarded from the courts to the Forensic Psychiatry and Psychology Unit at the USP Clinical Hospital. A clinical interview and application of cognitive tests was conducted. Despite the depression, significant cognitive losses that would prevent return to his professional assignments were not detected. The neuropsychological assessment has been shown to be an important tool in the forensic context, as it assists with diagnostic value for clarification of functional aspects in the various psychopathological areas in terms of disabilities or potentialities.
\end{abstract}

\section{RESUMO}

Assuntos relacionados à saúde mental na corte vêm demandando crescente participação de psicólogos. Sob este mote, apresentamos uma aplicação de um assessment neuropsicológico em um caso de reversão de aposentadoria por invalidez. Trata-se do caso de um juiz de 35 anos, que chegou à nossa Unidade de Tratamento Forense Psicológico e Psiquiátrico, no Hospital das Clínicas da Universidade de São Paulo. Para suprir a demanda, inicialmente conduzimos uma entrevista clínica e, em seguida, aplicamos uma bateria neuropsicológica, a partir da qual foi revelada a inexistência de limitações do desempenho cognitivo, as quais recomendariam a reafirmação do afastamento do profissional. Tal como revelado, o uso adequado do assessment neuropsicológico mostra-se uma importante ferramenta em contexto forense, auxiliando o esclarecimento de aspectos funcionais do diagnóstico, em vários contextos psicopatológicos.

1 University of São Paulo (USP), Clinical Hospital, Institute of Psychiatry.
2 Federal University of São Paulo (Unifesp), Medical School, Clinical Neuroscience Lab.
3 USP, Institute of Psychology.
4 Methodist University of São Paulo (Umesp), Post-graduate Program in the Psychology of Health.

Address for correspondence: Alvaro Machado Dias Laboratório Interdisciplinar de Neurociências Clínicas (LiNC) Rua Pedro de Toledo, 669, $3^{\circ}$ andar Vila Clementino 05039-032 - São Paulo, SP, Brazil

Emails: alvaromd@usp.br; alvaromd@unifesp.br 


\section{INTRODUCTION}

The impact of mental illness for personal and professional lives of the people has been investigated for a long time?. Ceasing to work due to debilitating neuropsychiatric disease has increasingly required the participation of doctors and psychologists to clarify the facts, and with the development of neuropsychology this requirement has become more frequent $^{2-5}$. This is a theoretical and practical shift, once not only the symptoms, but also the cognitive changes and functional disability are now being taken into account when attesting incapacity, as in episodes of depression, for example ${ }^{6}$.

Between the years of 2008 and 2012, 82.980 disability retirements due to mental or behavioral disorders were registered in Brazil, from which 39.63\% were from depressive spectrum (i.e. F 31: Bipolar disorder type II, F 32: major depressive disorder (single episode) and F 33: major depressive disorder (recurrent) representing the amount of de R\$ 37.607.918, 63 (nearly 17 million dollars), 42.87\% of the total spent with disability retirements due to mental or behavioral disorders ${ }^{7}$. In Europe a 12 month neuropsychiatric disorders prevalence study was conducted by Wittchen et al. ${ }^{8}$, comprising 167 millions of cases in 27 countries, showed that unipolar depression as the second most frequent mental disease, with 30.3 million cases, and has the highest disease burden, measured by disability adjusted life years (DALY). In Brazil, the frequency ratio is $36 \%$ larger for bipolar affective disorders and major depression (recurrent) and 9\% for major depression (single episode). The same pattern was observed in the European study, in which the DALY rate per 10.000 persons regarding unipolar depression is $90 \%$ higher for women in comparison with men?.

Apart from the socioeconomic burden, related to disability retirement, comprising expenses related to pensions, treatments and the loss of productive force, early retirement also have significant effects over the individuals mental health. Retired individuals present higher rates of anxiety and depression disorders than those with the same age who are still working, these discrepancies are gender related and more pronounced at earlier ages ${ }^{9-11}$. Retiring may affect also cognitive functioning ${ }^{12}$. These aspects taken together show the growing importance of accurate and comprehensive evaluations, a scenario in which the neuropsychological assessment may contribute.

The introduction of neuropsychology into forensics involves a fundamental difference in relation to clinical practice. In the clinical setting, the objective of assessment is to determine the existence or not of a dysfunction of cognitive functions, considering a rehabilitation plan. Forensic neuropsychology should respond to a legal questions, that is, if this dysfunction affects or does not affect the understanding and self-determination ability of that person in a forensic situation, as well as his or her ability to perform specific tasks, like the usual work ${ }^{5,13}$
The use of forensic neuropsychological assessment has been highlighted in recent years given its ability to contribute to the understanding of human conduct, whether criminal or not, in the scope of participation in biological, psychic, social and cultural instances as modulators of the expression of behavior ${ }^{5,13}$

In this article, we present an account of a case in which neuropsychological assessment in the area of forensics was used for reversal of disability retirement due to depression.

\section{CASE REPORT}

Mr. C. is 35 years old, and has a background in law and retired due to disability, in November 2008. He reports that in 2006 he left his role as public prosecutor due to cognitive complaints (difficulty concentrating and memory) resulting from depression. The clinical interview presented an appropriate level of consciousness and vigilance capacity. Attention was spontaneous and voluntary maintained and long-term memory was also preserved. He was capable of orienting himself in time and space, and showed intact awareness of himself and others. He presented preserved concrete thinking and abstract reasoning, without changes of course or speed of ideas of presenting delusional content, and showed mild depressed mood. No perception or psychomotor changes. Appropriate language with extensive vocabulary.

Mr. C. reported that he had always been a shy child, timid, who liked to read. His mother had a history of depression since his childhood. In adolescence he was a popular person, but from times to times got more reclusive and he studied intensely at university. After college, reports anxiety in relation to gaining financial independence with the first depressive symptoms emerging. Mr. C. felt anguished and had bouts of anxiety. These symptoms occurred during periods of the day, including in his work environment. In evaluation with medication professionals, he followed the indicated treatment, showing that he passed through different psychiatrists and changed the treatment carried out until then. He used fluoxetine (20/mg), sertraline hydrochloride (50/mg), amitriptyline hydrochloride $(25 / \mathrm{mg})$ and topiramate (200 $\mathrm{mg}$ ) with little development that culminated with the disability retirement. After four years away, he now realizes that he can return to his activities and requests reversal of his retirement, being forwarded to the Forensic Unit of USP Clinical Hospital. During the evaluation period he reported that he was not taking medication. Procedures: Clinical interview as a participant in question and signature of informed consent; assessment of intellectual level through the Wechsler Adult Intelligence Scale-III (WAIS-III) and copying and reproduction memory test (Rey Complex Figures) and measure of mental flexibility and executive functions through the Wisconsin Card Test (WCST). 
In relation to verbal functions (WAIS-III), he achieved superior performance in Vocabulary, Similarities, Arithmetic, Number and Letter Sequences subtests, and high average performance in the Comprehension subtest; and highly superior performance in Numbers and Information subtests that involves both the area of language understanding, and the memory associated with the primary auditory cortex and angular gyrus in the posterior superior portion of the temporal lobe.

In the evaluation of executive functions (WAIS-III) in Completion of Figures, Codes, Arrangement and Framing of Objects subtests, Mr. C. presented high average performance, in the Matrix Reasoning subtest he showed superior performance. In the Block Design subtest, he achieved a highly superior performance, in this activity which requires the ability to reproduce something that has been learned or even visually presented, related to the parietal lobe.

In a check of memory via the Rey Complex Figure Test, his performance in copying the figure fell in the high average range $\left(70^{\text {th }}\right.$ percentile), while his ability to recall the figure was in the low range ( $10^{\text {th }}$ percentile), indicating his difficulty in remembering the stimulus when prompted. It is known that the executive functions play an important role in planning and decision-making processes, and are directly connected to the frontal lobe and can be substantially changed by anxiousness or depressiveness ${ }^{14-16}$.

Table 1 contains results regarding flexibility and mental functions. It is observed that Mr. C. presented results in the lower middle range in for Perseverative Answers and Perseverative Errors, and average performance for Error Answers and Non-Perseverative Errors. These results are related to the ability to formulate an objective, plan, execute plans directed at the objective in an effective way, with spontaneous selfmonitoring spontaneous and with safety associated with frontal lobe functions.

Table 1. Raw score, standard score, T score, percentile score and range for number of error responses, perseverative responses, non-perseverative errors and perseverative Errors - WCST

\begin{tabular}{lccccc}
\hline & $\begin{array}{c}\text { Raw } \\
\text { score }\end{array}$ & $\begin{array}{c}\text { Standard } \\
\text { score }\end{array}$ & TScore & Percentile & Range \\
\hline Error responses & 17 & 95 & 47 & 37 & $=$ \\
Perseverative responses & 12 & 88 & 42 & 21 & $=\downarrow$ \\
Non-perseverative errors & 6 & 100 & 50 & 50 & $=$ \\
Perseverative errors & 11 & 88 & 42 & 21 & $=\downarrow$ \\
\hline
\end{tabular}

Legend: $=$ (middle); $=\downarrow$ (lower middle)

\section{DISCUSSION}

The spectrum of investigation into brain function and behavioral expression is part of a context that touches on history, psychology and neurology and, more recently, neuropsychology.
The advances in psychiatry, psychology and in neuropsychology, contributed a great deal for the justice system. When dealing with human beings, this knowledge is of great help for the lawmen to understand sometimes relevant details, thus richly valuing the role of forensic sciences. These sciences are different in many ways, but in the forensic context it is central that they can work together, as the collaboration among mental health professionals enhances the reliability of the documents, lending credibility to the justice decisions ${ }^{17}$.

For Brown ${ }^{18}$ by 2,020 depressive disorders are expected to be the second highest cause of disease burden worldwide. Although cognitive deficits are the usual residual symptoms ${ }^{19}$, they are mistakenly viewed as simple epiphenomena of the disorder, once not always impair general function of depressed patients ${ }^{20}$.

This is illustrated in this case of the request for retirement reversal by Mr. C., who claimed to be able to return to his job despite the presence of mild depression. There were favorable conditions for the use of neuropsychological assessment. The request filed by Mr. C. is ensured by the Brazilian social security law under article 46 of Decree 3.048/99 (Brazilian Law). If an individual judges that he is fit for the job, he should request a new medical-forensic assessment. If recovery for the labor activity is confirmed, retirement will be canceled.

The possibility of the depression leading to cognitive changes in many patients is undeniable. Several authors have reported on occurrence of cognitive failures linked to depression, even during periods in which the patients are euthymic ${ }^{15}$.

Therefore, in forensic contexts, a more functional assessment of the situation seems to have relevance for follow-up of the process. Mr. C. presented general intelligence functioning well above expected for his age and education, not showing flaws or cognitive disability that could interfere in the quality of intellectual functioning, as well as in the inability to return to his work, result different from the literature findings ${ }^{14}$. The hypothesis can be raised that, compared with his own results, the patient shows a better performance in his verbal functions than his execution functions, but without prejudice to these, differing from the literature in relation to the euthymic phase $^{16}$.

Although studies show that patients with depression tend to have deficits when compared to normal individuals in regards to visual-spatial skills, short-term memory and attention, as well as mental flexibility and processing speed ${ }^{3}$, such deficits were not perceived in the functioning of the patient described here.

In relation to the investigation of short-term memory (working memory), he presented results within the expected range for his age/education, different from the litera-

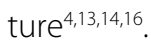


Mental flexibility, evaluated through the WCST, revealed that Mr. C. is able to change his mode of action in the environment through the response to his actions.

\section{CONCLUSION}

The data suggested that despite the depression, Mr. C. showed no significant cognitive impairments that prevent him from resuming his professional duties. Thus, although psychiatric evaluation would consider him mildly depressed, the neuropsychological complementary evaluation ended up being relevant. Moreover, it highlights the critical importance of a rigorous neuropsychological assessment in the forensic context, as it contributes value to diagnostic clarification of the functional aspects in various areas of psychopathology in terms of disability and potentialities. The possibility of having he working again is of economic and social importance to the country, as much as to himself.

That said, one thing that should be considered is the possibility of using neuroscientific methods to assess mental impairments in such contexts. This case is "special" in the sense that the subject's will was aligned with the public interest; in opposed situations, one may consider that a subject could try to score as low as possible in the tests to provide evidences in favor of an absent disability. The use of neural correlates of attention and preconscious responses to sensorial stimuli could overcome the limitations of present methods. Another alternative - which could and should be combined with this one - is the introduction of a new set of neuropsychological tools, constructed to hamper inferences about what is exactly being measured. We are working on the development of paradigms of the kind and will hopefully be able to release this new class of tests in the near future, for we believe the collaboration between psychiatrists and psychologists has the potential to increase both the credibility and utility of forensic services to the courts.

\section{INDIVIDUAL CONTRIBUTIONS}

Camila Monti - Contributed in study design, in data collection, analysis of results, drafting of the article and approved its final version.

Fabiana Saffi - Contributed in study design, analysis of results and preparation of the article and approved its final version.

Daniel Martins de Barros - Contributed in study design, the preparation of the article and approved its final version.

Alvaro Machado Dias - Contributed in designing the study, drafting of the article and approved its final version.
Henrique Teruo Akiba - Contributed in designing the study, revising it and approved its final version.

Antonio de Pádua Serafim - Contributed in designing the study, revising it and approved its final version.

\section{REFERENCES}

1. Van Dongen CJ. Quality of life and self-esteem in working and nonworking persons with mental illness. Community Ment Health J. 1996;32(6):535-48.

2. Gierowski J. Complex expertise on the psychiatric health of a criminal. Psychiatr Pol. 2005;40(1):5-17.

3. Heilbrun K, Marczyk GR, DeMatteo D, Zillmer EA, Harris J, Jennings T. Principles of forensic mental heal th assessment implications for neuropsychological assessment in forensic contexts. Assessment. 2006;10(4):329-43.

4. Hom J. Forensic Neuropsychology: are we there yet? Arch Clin Neuropsychol. 2003;18(8):827-45.

5. Verdejo A, Alcázar-Córcoles M, Gomez-Jarabo G, Pérez-García M. Guidelines for the scientific and professional development of forensic neuropsychology. Rev Neurol. 2004;39(1):60-73.

6. Harvey PD. Cognitive impairments in major depression and bipolar disorders. Psychiatry (Edgmont). 2007;4(1):12-4.

7. Brasil. Ministério da Previdência Social. Base de Dados Históricos de Acidente do trabalho. Available at: <http://www3.dataprev.gov.br/aeat/>. Accessed on: 20 ago. 2014.

8. Wittchen HU, Jacobi F, Rehm J, Gustavsson A, Svensson M, Jönsson B, et al. The size and burden of mental disorders and other disorders of the brain in Europe 2010. Eur Neuropsychopharmacol. 2011;21(9):655-79.

9. Canizares JCL, Jacob Filho W. Senility risk factors upon retirement transition. Rev Bra Geriatr Gerontol. 2011;4(3):425-32.

10. Butterworth P, Gilla S, Rodgersb B, Ansteya KJ, Villamil E, Melzer D. Retirement and mental health: analysis of the Australian national survey of mental health and well-being. Soc Sci Med. 2006;62(5):1179-91.

11. Melzer D, Buxton J, Villamil E. Decline in Common Mental Disorder prevalence in men during the sixth decade of life. Evidence from the National Psychiatric Morbidity Survey. Soc Psychiatry Psychiatr Epidemiol. 2004;39(1):33-8.

12. Bonsang $E$, Adam S, Perelman S. Does retirement affect cognitive functioning? J Health Economics. 2012;31(3):490-501

13. Fernández GS. Forensic neuropsychology: principal issues and applications. Rev Neurol. 2001;32(8):783-7.

14. Bhardwaj A, Wilkinson P, Srivastava C, Sharma M. Cognitive deficits in euthymic patients with recurrent depression. J Nerv Ment Dis. 2010;198(7):513-5.

15. Harvey PD. Mood symptoms, cognition, and everyday functioning: in major depression, bipolar disorder, and schizophrenia. Innov Clin Neurosci. 2011;8(10):14-8.

16. Malhi GS, Ivanovski B, Hadzi-Pavlovic D, Mitchell PB, Vieta E, Sachdev P. Neuropsychological deficits and functional impairment in bipolar depression, hypomania and euthymia. Bipolar Disord. 2007;9(1-2):114-25.

17. Serafim AP, Barros DM. Interdisciplinary evaluation: interface between psychiatry and forensic psychology. J Bras Psiquiatr. 2014;63(1):86-7.

18. Brown P. Effective treatments for mental illness are not being used, WHO says. BMJ. 2001;323:769.

19. Pedrelli P, Baer L, Losifescu DV, Fava M. Relationship between residual symptoms of depression and self-reported cognitive impairment. CNS Spectr. 2010;15(1):46-51.

20. Austin MP, Mitchekk P, Goodwin GM. Cognitive deficits in depression possible implications for functional neuropathology. Br J Psychiatry. 2001;178:200-6. 